\title{
Prevalence of Common Diseases in a Perturbed Wetland Community of Okorombokho in the Niger-Delta Region, Nigeria
}

\author{
Atting $\mathrm{I}^{1 *}$, Akpan $\mathrm{I}^{2}$, Umoh $\mathrm{G}^{2}$ and Bassey $\mathrm{E}^{3}$ \\ ${ }^{1}$ Department of Medical Microbiology and Parasitology, University of Uyo, Nigeria \\ ${ }^{2}$ Center for Wetlands and Waste Management Studies, University of Uyo, Nigeria \\ ${ }^{3}$ Department of Obstetrics and Gynaecology, University of Uyo, Nigeria
}

*Corresponding author: Inyang Atting, Department of Medical Microbiology and Parasitology, Faculty of Clinical Sciences, University of Uyo, Uyo, Nigeria, Email: dr_atting@yahoo.com

\section{Research Article}

Volume 2 Issue 2

Received Date: March 15, 2019

Published Date: April 01, 2019

DOI: $10.23880 /$ jqhe- 16000117

\section{Abstract}

Disease outbreak is a major challenge facing many coastal and rural areas due to factors such as inadequate safe water supply, poor sanitation and living conditions. These conditions make human beings vulnerable to infections of varying types, and if neglected, can result in loss of lives. Against this backdrop, prevalence of common diseases in a perturbed wetland of Okorombokho community in Eastern Obolo LGA, Akwa Ibom State, Nigeria was investigated. A stratified random sampling technique was used in choosing the study population. A total of 200 questionnaires were retrieved from the respondents and this, together with the Focus Group Discussion (FGD) served as the instruments of data collection. The common diseases that were prevalent in this community in order of increasing magnitude were: Malaria, $87.0 \%$ in adults and $44.0 \%$ in children, Typhoid fever, $24.0 \%$ in adults and $13.5 \%$ in children; Diarrhea, $11.0 \%$ in adults and $30.0 \%$ in children; Dysentery, $15.0 \%$ in adults, and 22.5\% in children; while Cholera in adults and children was $8.0 \%$ and $4.0 \%$, respectively. The study showed that lack of potable water supply, use of aquatic ecosystems as dumpsites for wastes, open defecation in water, poor sanitary and environmental conditions and lack of well-equipped modern health care facilities were the enabling factors for the prevalence of these diseases in this community. This calls for prompt responses from the governments, environmental and health protection agencies and community-based organizations in the prevention, control and eradication of these diseases by providing necessary health facilities with adequate personnel and other needed health resources that will ensure that the coastal and rural dwellers live a healthy life.

Keywords: Prevalence; Common Diseases; Malaria; Breeding; Demography; Health Care 


\section{Journal of Quality in Health Care \& Economics}

Abbreviations: FGD: Focus Group Discussion; IDs: Infectious Diseases; NCDs: Non-Communicable Diseases; GBDS: Global Burden of Disease Study; DALYs: DisabilityAdjusted Life Years; SPDC: Shell Petroleum Development Company of Nigeria; SPSS: Statistical Package for Social Sciences.

\section{Introduction}

Globally, infectious diseases have always played a major role in the world history, and as such are observed in time and place and configured in terms of ecology and demography, available medical knowledge, cultural values and collective experience [1]. Settlements in the coastal environments of some African countries including Nigeria (particularly the Niger-Delta region) are affected by epidemics of infectious diseases which usually result in high mortality rates. As human influences extend across the globe, natural habitats (such as wetlands) and it species, communities, and ecosystems that they contain are increasingly under threat. This is because land use/land cover change and habitat fragmentation are consistently listed among the most significant threats to biodiversity, and are also the key drivers of the current high extinction rate of species [2].

The worldwide wetland resource is huge and large including rivers, reefs lakes, river, tidal flats, and artificial reservoirs and rice field. Accordingly, wetland functions include recharge of the hydrology of groundwater, sediment protection and trapping, flood and erosion control, treatment and recycling of waste water, and provision of breeding and rearing ground for natural habitats, animals and aquaculture resources. They are also useful for farming, especially for the cultivation of rice and fish [3].

Historically, infectious diseases (IDs) have been the most important contributor to human morbidity and mortality until in very recent times, when noncommunicable diseases (NCDs) began to rival, and sometimes exceed, infections. Today, IDs still account for a large proportion of death and disability worldwide and in certain regions remain the most important cause of ill health. The Global Burden of Disease Study (GBDS) estimates that, in the year 2000, infectious diseases were responsible for $22 \%$ of all deaths and $27 \%$ of disabilityadjusted life years (DALYs) worldwide [4]. Although infectious diseases can affect people of all ages, they impose a particular burden on the young, notably on children under five. This is not only because younger age groups have a lower prevalence of NCDs, but because they are more susceptible than adults to new infections, lacking the protective mechanisms to reduce the impact of these illnesses $[5,6]$.

Consequently, in regions where a high proportion of the population is made up of young people of Africa, Latin America and many other developing regions infectious diseases usually extract a relatively high toll on the population. For example, GBDS estimates for 2002 were that infectious diseases were responsible for $52 \%$ and $50 \%$, respectively of all deaths and DALYs in sub-Saharan Africa [4]. In sub-Saharan Africa, respiratory infections, diarrheal diseases, HIV/AIDS, TB and malaria account for roughly similar proportions of total ID deaths Lopez, et al. In addition, rates of specific infectious diseases are generally much higher in poor countries, regardless of the relative importance of these diseases. Therefore, in both relative and absolute terms, IDs are a considerably higher burden in low-income than high income countries. An analysis of GBDS data concludes that the poorest $20 \%$ of the world's population experiences a far higher burden of infectious disease compared to the remaining $80 \%$ of the world's population [7].

Increase in human populations in some coastal areas has exerted enormous pressure on the provision of safe living habitats to humans. For example, the Okorombokho community supports a vast range of human activities and businesses, as well as serving as one of the most inhabitable areas by humans. Also, its environs experience poor sanitation state due largely to the unfriendly release of toxic environmental pollutants from different humanly generated sources into its surroundings. The pattern of settlement in the NigerDelta Region is largely determined by the availability of dry land and the nature of the terrain [8]. Low relief and poor ground drainage are the primary factors responsible for the low number of large settlements in the region. The larger settlements are found in the interior parts of the community that has better drainage conditions and accessibility. Most rural settlements lack essential amenities. The level of infrastructure and industrial development demanded can hardly be sustained by the fragile ecosystems in the core Niger-Delta, particularly in the unique mangrove swamp zone. Human societies over the ages have depleted natural resources and degraded their local environments. A delicate balance exists between the human population in the Akwa Ibom State and its fragile ecosystem. There is a strong feeling in the region that the rate of environmental degradation is pushing the Delta towards ecological disaster. The lack of land makes settlement difficult and costly, forcing some 


\section{Journal of Quality in Health Care \& Economics}

communities to engage in uncontrolled land reclamation [9].

There has been a long history of the association of wetlands with infectious disease. The alteration of wetlands or environmental management of wetlands for the control of disease is well documented and continues to be the main method of reducing the risk of disease. In addition, the development of water resources for a wide range of human activities such as energy and agricultural production has increased the need for mitigating the effects caused by such construction. The construction of water development projects will continue long into the future. At present there is considerable reference to disease and water development projects [10]. The main parasitic diseases associated with water development projects are schistosomiasis, lymphatic filariasis, onchocerciasis, and malaria. These four diseases have been given priority by the World Bank. There are two separate categories of wetlands that we are concerned with that challenge us to take a more eco systemic approach to health. The first is the water development projects that increase the amount of wetlands and/or change the seasonality of the wetlands due to water regulation. The second is the modification of natural wetlands [11].

The second major wetland issue involves natural wetlands and disease. These are areas where vectors or agents of infectious diseases are present. The protection and use of wetlands has direct and indirect effects on human health. However, our ability to quantitatively assess the health value of wetlands and modifications thereof is limited [12]. In the past, wetlands have been modified to eliminate or reduce the risk of disease. This is particularly the case for malaria [13]. However, recent work has shown that control of mosquito vectors can be achieved within the context of preservation and wise management of wetlands. In particular, it has been shown that the use of ecological mapping techniques to define breeding sites and design control strategies can dramatically reduce the use of insecticides in wetlands and has the potential to decrease environmental modifications [14].

More so, the most successful infectious disease control programmes conducts basic and applied research on the biology of the vector and pathogen in order to obtain a basic understanding of the dynamics of disease transmission before implementing control. These data are the foundation for control strategy development. However, the sociological and behavior components of disease are often neglected. Much more needs to be done to better understand the function and structure of wetlands and the biological niches of vectors and pathogens within them. One of the main challenges is to integrate wetland ecosystem research with disease ecology research. Recent attempts have been made in ecoepidemiological research [15]. Many studies only consider ecological risk factors and do not incorporate the spatial/temporal relationship of the infectious diseases with wetland ecosystems. There is an urgent need for long-term studies with an ecosystem approach to wetland and disease issues. Scientists in public health, wetland ecology, and conservation need to work together to form integrated research teams. There is also an urgent need for an economic valuation of wetland resources [16]. The purpose of the study was principally aimed at assessing the prevalence of common diseases in a perturbed wetland community of Okorombokho in Eastern Obolo Local Government Area of Akwa Ibom State, Nigeria as basis for determining the major causes of these diseases and making recommendations on the ways of controlling disease outbreaks in the study area.

\section{Methodology}

\section{The Study Area}

Okorombokho community in Eastern Obolo LGA of Akwalbom State, Nigeria was chosen for this study. It is located at the east of Imo River and occupies the Southern Niger-Delta fringe between Imo River and Qua Iboe River Estuaries. It lies between latitude $4^{\circ} 30^{\prime}$ North and longitude $7^{\circ} 35^{\prime}$ East. The population of Eastern Obolo LGA is 109,052 (NPC, 2007). The area lies within the tropical rainforest zone and has two major seasons which include a rainy season (May to October) and a dry season (November to April). Annual rainfall ranges between $2,000 \mathrm{~mm}$ and $2,400 \mathrm{~mm}$. About $90 \%$ of the area is waterlogged and the major occupations of the people are fishing and fish processing. The Local Government Area plays host to Shell Petroleum Development Company of Nigeria (SPDC), one of the multi-national oil companies which has witnessed a number of major and minor oil spills within the past three decades (Figure 1) [16]. 


\section{Journal of Quality in Health Care \& Economics}

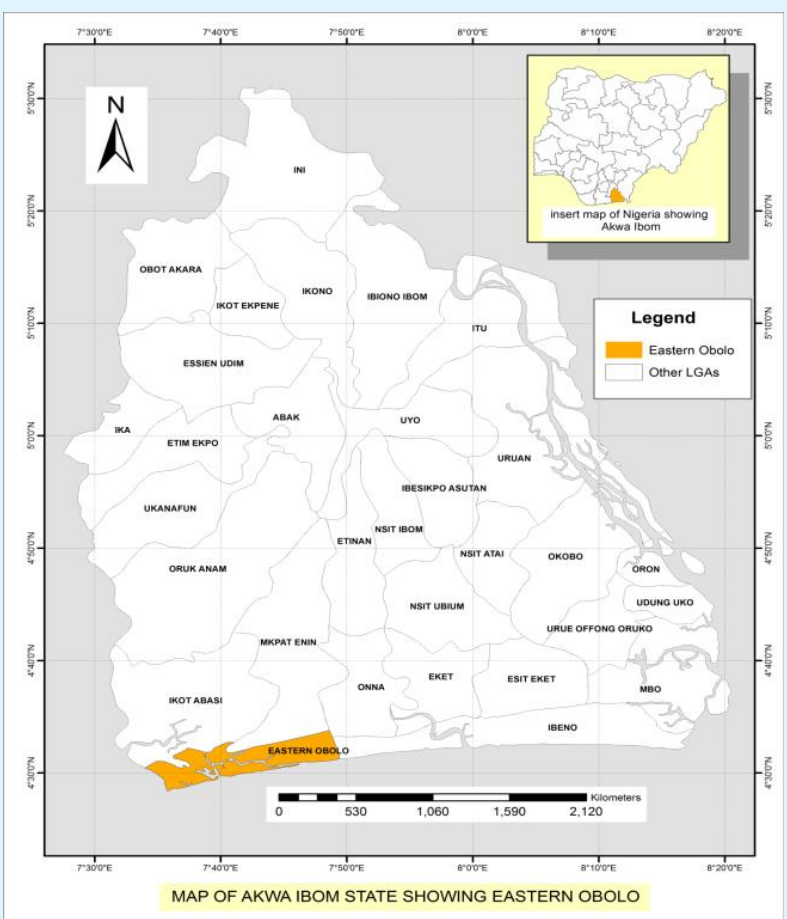

Figure 1: Map of Akwa Ibom State showing Eastern Obolo Local Government Area.

\section{Ethical Issues}

Informed consent was obtained from the Village Council where cross sections of the village heads, chiefs, youths and other village dwellers were assembled and informed about the study that was to be conducted and the benefits that will be derived at the completion of the study.

\section{Method of Data Collection}

Data used in this study was collected using a structured questionnaire which was distributed to the different respondents in the study location. Information obtained from the retrieved questionnaires were carefully sorted out and used as data in the study. Also, Focus Group Discussion (FGD) sessions were held with the men, women, traditional leaders and other opinion leaders residing in the community. The FGD sessions were held to exhaustively discuss and elicit information on their knowledge of the prevalence of some common prevailing diseases within their households, possible causes of these diseases, the utilization and non-utilization of available health care facilities as well as their views on available methods of wastes generation, disposal and management as well as their attitudes toward the utilization of modern health care facilities. Other issues discussed were centered on household hygiene, sources of consumable potable water, availability of toilet facilities in households and the presence of disease causing vectors and organisms within the community and its environs. This discussion also covered the roles played by the community leaders and those of the various local associations in the promotion of sound and good health in their communities.

\section{Study Population}

A stratified random sampling technique was used in the selection of the study population which comprised of the various respondents in the study location. A total of 400structured questionnaires were administered to randomly selected population but only 200 were retrieved on completion. These retrieved question nares were stored, prior to data analysis and presentation.

\section{Statistical Analysis}

Data obtained were analyzed descriptively using frequencies and simple percentages and relationships between each socio-demographic variable and reported cases of each component of prevalent disease and gender 


\section{Journal of Quality in Health Care \& Economics}

was tested using Chi-square. Moreover, univariate analysis of the association between disease prevalence and each of its possible risk factors was also determined with the use of Chi-square statistical test. Furthermore, multivariate analysis using multiple logistic regression models which incorporated all possible risk factors, while adjusting for the effect of possible confounders such as educational background and marital status was also applied. This analysis was done separately for adults and children. Based on the results of multiple logistic regression models, statistical computations were enhanced with the Statistical Package for Social Sciences (SPSS 20). P-values less than 0.05 were considered to be statistically significant.

\section{Results and Discussion}

\section{Results}

Statistical analysis was performed using SPSS for windows (version 20). Data were analyzed utilizing Chi- square and Fisher's exact test for measure of association between the dependent variable (disease status) and the independent variables (both socio-demographic characteristics and risk factors). Tables were expressed in numbers of observation with prevalence in percentages.

\section{Health Facility Availability, Accessibility and Utilization}

Table1 shows that the health facility availability is $96 \%$ to respondents' households with the location of a Health Centre in the community. The respondents revealed that the use of over counter medication (Medicine store) was their usual means of treatment and this was made up of $64 \%$ of the respondents. The respondents were not satisfied with the number of health workers available to them, $73 \%$ and thus only managed to visit the health facility for their health and health-related needs yearly, $42 \%$ and monthly, 27\% (Table 1).

\begin{tabular}{|c|c|c|c|}
\hline Variables & Responses & Frequency & Percentage (\%) \\
\hline \multirow{3}{*}{ Health Centre } & No & 8 & 4 \\
\hline & Yes & 192 & 96 \\
\hline & Total & 200 & 100 \\
\hline \multirow{5}{*}{ Mode of Treatment } & Visit Hospital & 54 & 27 \\
\hline & Medicine Store & 128 & 64 \\
\hline & Native Doctor & 6 & 3 \\
\hline & Self-Medication & 12 & 6 \\
\hline & Total & 200 & 100 \\
\hline \multirow{4}{*}{ Drug Supply enough? } & No & 113 & 56.5 \\
\hline & Yes & 46 & 23 \\
\hline & Don't Know & 41 & 20.5 \\
\hline & Total & 200 & 100 \\
\hline \multirow{4}{*}{ Health Workers enough? } & No & 146 & 73 \\
\hline & Yes & 27 & 13.5 \\
\hline & Don't Know & 27 & 13.5 \\
\hline & Total & 200 & 100 \\
\hline \multirow{6}{*}{ Visit to Health facility } & Daily & 3 & 1.5 \\
\hline & Weekly & 18 & 9 \\
\hline & Monthly & 54 & 27 \\
\hline & Yearly & 84 & 42 \\
\hline & Others & 41 & 20.5 \\
\hline & Total & 200 & 100 \\
\hline
\end{tabular}

Table 1: Distribution, Mode of Treatment, Availability and Accessibility of Health Facilities to Respondents' Households in Okorombokho. 
Incidence and Prevalence of Diseases in Respondents' Households

The incidence of diseases in the study area is shown on Table 2. The incidence of malaria was highest, $87.0 \%$ and $44.0 \%$ for adults and children, respectively. The rate of infection with diarrhea in children was $30 \%$ while dysentery in adults was $15 \%$.

\begin{tabular}{|c|c|c|}
\hline Diseases & Adults Frequency (\%) & Children Frequency (\%) \\
\hline Malaria & $174(87.0)$ & $88(44.0)$ \\
\hline Typhoid fever & $48(24)$ & $27(13.5)$ \\
\hline Diarrhea & $22(11.0)$ & $60(30.0)$ \\
\hline Dysentery & $30(15.0)$ & $14(22.5)$ \\
\hline Measles & 0 & $8(4.0)$ \\
\hline Cholera & $16(8.0)$ & $7(3.5)$ \\
\hline Polio & 0 & 0 \\
\hline TB & $2(1.0)$ & $11(5.5)$ \\
\hline Yellow Fever & $4(2.0)$ & 0 \\
\hline HIV & $4(2.0)$ & 0 \\
\hline Chicken Pox & $11(5.5)$ & 0 \\
\hline River Blindness & $2(1.0)$ & 0 \\
\hline Diabetes & $2(1.0)$ & 0 \\
\hline Cancer & $2(1.0)$ & 0 \\
\hline
\end{tabular}

Source: Primary Health Centre, Okoroete, Eastern-Obolo LGA.

Table 2: Incidence of Diseases in Respondents' Households in Okorombokho.

\section{Distribution of Malaria Infection in Respondents Household}

Table 3 shows distribution of malaria infection across the Socio-demographic Characteristics in the study area. The association between the socio-demographic variables and the distribution of malaria infection shows that the difference in the prevalence between the category of the various variables except sex (gender) was statistically not significant $(p>0.05)$. The prevalence was higher in females (81.3\%), this showed statistical significant difference, and the odd of females being infected with malaria was three times that of male respondents.

\begin{tabular}{|c|c|c|c|c|c|c|}
\hline Variables & Category & No. & Frequency (\%) & Chi-square & p-value & OR (95\%CI) \\
\hline \multirow{3}{*}{ Sex (Gender) } & Male & 109 & $64(58.7)$ & 11.84 & 0.001 & 1 \\
\hline \multirow{4}{*}{ Age groups } & Female & 91 & $74(81.3)$ & & & $3.0(1.60-5.87)$ \\
\cline { 2 - 7 } & $20-29$ & 67 & $47(70.1)$ & 2.57 & 0.46 & 1 \\
\cline { 2 - 7 } & $30-39$ & 64 & $41(64.1)$ & & & $0.76(0.37-1.57)$ \\
\cline { 2 - 7 } & $40-49$ & 39 & $26(66.7)$ & & & $0.85(0.37-1.99)$ \\
\hline \multirow{3}{*}{ Marital status } & 50 above & 30 & $24(80.0)$ & & & $1.72(0.60-4.79)$ \\
\cline { 2 - 7 } & Married & 123 & $86(69.9)$ & 2.02 & 0.36 & 1 \\
\cline { 2 - 7 } & Single & 72 & $50(69.4)$ & & & $0.98(0.52-1.84)$ \\
\hline \multirow{3}{*}{ Education } & Divorced & 5 & $2(40.0)$ & & & $0.29(0.05-1.79)$ \\
\cline { 2 - 7 } & Primary & 52 & $37(71.2)$ & 7.6 & 0.06 & 1 \\
\cline { 2 - 7 } & Secondary & 98 & $72(73.5)$ & & & $1.12(0.53-2.37)$ \\
\cline { 2 - 7 } & Tertiary & 39 & $20(51.3)$ & & & $0.43(0.18-1.02)$ \\
\cline { 2 - 7 } & No Formal Education & 11 & $9(81.8)$ & & & $1.82(0.35-9.46)$ \\
\hline
\end{tabular}

Table3: Prevalence of Malaria in Respondents' Households in Okorombokho.

\section{Prevalence of Typhoid Fever Infections}

Table 4 shows the distribution of Typhoid infection across the Socio-demographic Characteristics in the study area. The prevalence of Typhoid within sociodemographic variables showed that the prevalence within the various age groups was different. The highest 


\section{Journal of Quality in Health Care \& Economics}

prevalence (41.0\%) was seen in age group 40-49 followed by age group 20-29 (26.9\%). The test of association showed that there was statistical significant relationship between the Age group and typhoid fever distribution $(p<0.05)$. The odd of been typhoid fever positive was highest in the age group age group 40-49 when compared to age group $20-29$ as a reference indicator. The prevalence of typhoid fever was higher in Single (33.3\%). The Odds of being typhoid fever infected in Single was twice that of Married.

\begin{tabular}{|c|c|c|c|c|c|c|}
\hline Variables & Category & No. & Frequency (\%) & Chi-square & p-value & OR (95\%CI) \\
\hline \multirow{2}{*}{ Sex (Gender) } & Male & 109 & $21(19.3)$ & 2.94 & 0.08 & 1 \\
\hline & Female & 91 & $27(29.7)$ & & & $1.77(0.92-3.40)$ \\
\hline \multirow{4}{*}{ Age groups } & $20-29$ & 67 & $18(26.9)$ & 11.4 & 0.01 & 1 \\
\hline & $30-39$ & 64 & $8(12.5)$ & & & $0.39(0.16-0.97)$ \\
\hline & $40-49$ & 39 & $16(41.0)$ & & & $1.89(0.82-4.37)$ \\
\hline & 50 above & 30 & $6(20.0)$ & & & $0.68(0.23-1.94)$ \\
\hline \multirow{3}{*}{ Marital status } & Married & 123 & $24(19.5)$ & 6.37 & 0.04 & 1 \\
\hline & Single & 72 & $24(33.3)$ & & & $2.06(1.06-4.00)$ \\
\hline & Divorced & 5 & 0 & & & 0 \\
\hline \multirow{4}{*}{ Education } & Primary & 52 & $7(13.5)$ & 6.03 & 0.11 & 1 \\
\hline & Secondary & 98 & $29(29.6)$ & & & $2.70(1.09-6.69)$ \\
\hline & Tertiary & 39 & $8(20.5)$ & & & $1.66(0.55-5.05)$ \\
\hline & No Formal Education & 11 & $4(36.4)$ & & & $3.67(0.85-15.88)$ \\
\hline
\end{tabular}

Table 4: Typhoid Fever Distribution Respondents' Households in Okorombokho.

\section{Prevalence of Diarrhea Infections in Households}

The distribution of diarrhea infection across the sociodemographic characteristics with varying differences in association between diarrhea infection and sociodemographic characteristics was not significant ( $p>0.05)$.

\begin{tabular}{|c|c|c|c|c|c|c|}
\hline Variables & Category & No. & Frequency (\%) & Chi-square & p-value & OR (95\%CI) \\
\hline \multirow{3}{*}{ Sex (Gender) } & Male & 109 & $14(12.8)$ & 0.83 & 0.36 & 1 \\
\cline { 2 - 7 } & Female & 91 & $8(8.8)$ & & & $0.65(0.26-1.64)$ \\
\hline \multirow{4}{*}{ Age groups } & $20-29$ & 67 & $10(14.9)$ & 6.32 & 0.09 & 1 \\
\cline { 2 - 7 } & $30-39$ & 64 & $9(14.1)$ & & & $0.93(0.35-2.47)$ \\
\cline { 2 - 7 } & $40-49$ & 39 & $3(7.7)$ & & & $0.48(0.12-1.84)$ \\
\cline { 2 - 7 } & 50 above & 30 & 0 & & & 0 \\
\hline \multirow{3}{*}{ Earital status } & Married & 123 & $9(7.3)$ & 5.98 & 0.05 & 1 \\
\cline { 2 - 7 } & Single & 72 & $13(18.1)$ & & & $2.79(1.13(6.92)$ \\
\cline { 2 - 7 } & Divorced & 52 & $2(3.8)$ & 6.32 & 0.09 & 1 \\
\cline { 2 - 7 } & Primary & 58 & $13(13.3)$ & & & $3.82(0.83-17.64)$ \\
\cline { 2 - 7 } & Secondary & $5(12.8)$ & & & $3.67(0.67-20.06)$ \\
\cline { 2 - 7 } & Tertiary & 39 & $2(18.2)$ & & & $5.56(0.69-44.67)$ \\
\hline
\end{tabular}

Table 5: Distribution of Diarrhea Infections in Respondents' Households in Okorombokho.

\section{Prevalence of Dysentery in Respondents' Households}

The prevalence of dysentery within sociodemographic variables showed that the prevalence within the various age groups was different. The highest prevalence $(26.9 \%)$ was seen in age group 20-29 years followed by age group 30-39years (14.1\%) as shown on Table 6. The test of association showed that there was statistical significant relationship between the age groups and dysentery distribution $(\mathrm{p}<0.05)$. The odd of being dysentery infection positive was highest in the age group 


\section{Journal of Quality in Health Care \& Economics}

20-29 years when compared to other age groups. There was no statistical significant association between other

socio-demographic variables and dysentery $(\mathrm{p}>0.05)$.

\begin{tabular}{|c|c|c|c|c|c|c|}
\hline Variables & Category & No. & Frequency (\%) & Chi-square & p-value & OR (95\%CI) \\
\hline \multirow{3}{*}{ Sex (Gender) } & Male & 109 & $19(17.4)$ & 1.11 & 0.29 & 1 \\
\cline { 2 - 7 } & Female & 91 & $11(12.1)$ & & & $0.65(0.29-1.45)$ \\
\hline \multirow{4}{*}{ Age groups } & $20-29$ & 67 & $18(26.9)$ & 11.1 & 0.001 & 1 \\
\cline { 2 - 7 } & $30-39$ & 64 & $9(14.1)$ & & & $0.45(0.18-1.08$ \\
\cline { 2 - 7 } & $40-49$ & 39 & $1(2.6)$ & & & $0.07(0.01-0.56)$ \\
\cline { 2 - 7 } & 50 above & 30 & $2(6.7)$ & & & $0.19(0.04-0.90)$ \\
\hline \multirow{3}{*}{ Earital status } & Married & 123 & $19(15.4)$ & 0.9 & 0.64 & 1 \\
\cline { 2 - 7 } & Single & 72 & $11(15.3)$ & & & $0.99(0.44-2.21)$ \\
\cline { 2 - 7 } & Divorced & 5 & 0 & & & 0 \\
\hline & Primary & 52 & $8(15.4)$ & 1.49 & 0.69 & 1 \\
\cline { 2 - 7 } & Secondary & 98 & $14(14.3)$ & & & $0.92(0.35-2.35)$ \\
\cline { 2 - 7 } & Tertiary & 39 & $5(12.8)$ & & & $0.81(024-2.70)$ \\
\cline { 2 - 7 } & No Formal Education & 11 & $3(27.3)$ & & & $2.06(0.45-9.49$ \\
\hline
\end{tabular}

Table 6: Distribution of Dysentery in Respondents' Household sin Okorombokho.

\section{Cholera across the Socio-Demographic Characteristics}

The prevalence of cholera within socio-demographic variables showed that the prevalence within the various age groups was different. The highest prevalence (11.9\%) was observed in age group 20-29 years followed by age group 30-39 years $(9.4 \%)$ as shown on Table 7 . The test of association showed that there was statistical significant relationship between the age group and cholera infection distribution $(\mathrm{p}<0.05)$. The odd of being cholera positive was highest in the age group 20-29 years when compared to other age groups. Thus, there was no statistical significant association between other socio-demographic variables and dysentery $(\mathrm{p}<0.05)$.

\begin{tabular}{|c|c|c|c|c|c|c|}
\hline Variables & Category & No. & Frequency (\%) & Chi-square & p-value & OR (95\%CI) \\
\hline \multirow{3}{*}{ Sex (Gender) } & Male & 109 & $6(5.5)$ & 2.03 & 0.16 & 1 \\
\hline & Female & 91 & $10(11.0)$ & & & $2.12(0.73-6.08)$ \\
\hline & $20-29$ & 67 & 8 (11.9) & 4.48 & 0.2 & 1 \\
\hline \multirow{3}{*}{ Age groups } & $30-39$ & 64 & $6(9.4)$ & & & $0.76(0.25-2.34)$ \\
\hline & $40-49$ & 39 & $2(5.1)$ & & & $0.40(0.08-1.98)$ \\
\hline & 50 above & 30 & 0 & & & \\
\hline \multirow{3}{*}{ Marital status } & Married & 123 & $16(13.0)$ & 12.51 & 0.002 & \\
\hline & Single & 72 & 0 & & & \\
\hline & Divorced & 5 & 0 & & & \\
\hline \multirow{4}{*}{ Education } & Primary & 52 & $2(3.8)$ & 4.05 & 0.22 & 1 \\
\hline & Secondary & 98 & $8(8.2)$ & & & $2.22(0.4-10.87)$ \\
\hline & Tertiary & 39 & $6(15.4)$ & & & $0.87(23.90)$ \\
\hline & No Formal Education & 11 & 0 & & & \\
\hline
\end{tabular}

Table 7: Distribution of Cholera in Respondents' Householdsin Okorombokho.

\section{Discussion}

The findings of this study revealed that there was varying prevalence of common diseases in Okorombokho wetland community due to anthropogenic perturbations of coastal environment. These diseases according to their order of magnitude and percentage composition were malaria, typhoid, dysentery, diarrhea and cholera. While malaria is caused by bites from female anopheles mosquitoes, typhoid, dysentery, diarrhea and cholera are 


\section{Journal of Quality in Health Care \& Economics}

water-borne and water- related diseases [17]. The high prevalence of malaria in a coastal region such as this is not unprecedented but rather agrees with the findings of Dayanand, et al. [18] in a related research. These scholars reported an endemic case of malaria in Mangaluru city area in southwestern coastal region of India for several decades with peak infections occurring during rainy season. The occurrence of malaria in the community was also gender-based as the female gender had a higher risk of malaria infection than the male gender and this was statistically significant $(\mathrm{p}<0.05)$. This result contradicts the findings of some scholars. For instance, Kimbi, et al. [19] reported a high prevalence of malaria in the male gender when compared with the females. This, they attributed to the fact that the males exposed their bodies more often than the female, especially when the weather is hot, thus, increasing their chances of being bitten by Plasmodium species infected mosquitoes.

Bates, et al. [20] also reported a higher risk of malaria infection in the males than in the females which they attributed to exposure, inherent and cultural determinants. However, the prevalence of malaria infection in the female gender in this study synchronizes with the findings of Brenyah, et al. [21] and Moshim, et al. [22]. While the former scholars attributed this high prevalence of malaria amongst females to the commercial activities (mostly trading) involving early and late outdoor activities of which more females are involved, the latter scholars attributed it to women being involved in common activities like cooking, farming, laundry, and washing of kitchen and other household utensils, which make them to spend long periods outdoors than indoors. These, according to the scholars increased their frequency of being bitten by infected mosquitoes.

In addition, the occurrence of malaria in both genders may suggest that its distribution is heterogeneous. The occurrence or distribution of malaria was not statistically significant $(\mathrm{P}<0.05)$ across the age groups, marital and educational statuses. A high prevalence of malaria was also observed in adults than in children. This may insinuate that the adults are more involved in outdoors day-to-day activities such as farming, fishing and trading that will lead to their being bitten by infected mosquitoes more than the children. Also the protection and prevention of children by the parents by wearing them protective clothing against the malaria vector may further expound the low malaria occurrence rate in children within this region [23].
The prevalence of typhoid fever and dysentery in this community were observed across the various age groups to be statistically significant $(p<0.05)$. The occurrence of these infectious diseases across various age groups may underscore their wide distribution in all ages. Their highest prevalence was observed among people belonging to the age range of 20-29 years. The vulnerability of people in this age group to these diseases may invariably point to poor hygienic practices commonly associated with individuals within this age range in the study area. The occurrence of other diseases such as diarrhea, dysentery and cholera in this community is not surprising as studies have shown that they are also water-borne and water-related $[24,25]$. The increased prevalence of these diseases in this community is not unrelated to inadequate and incompetent management of water resources, scarcity or non-availability of treated pipe-borne water and poor waste disposal systems. From the FGD, it was realized that several open water bodies got contaminated at source due to inflow of sewage. According to Deepali, et al. [26], human health can be affected by drinking polluted water either directly or by use of such water for drinking, cooking food (that is not properly cooked/ boiled) or use for the purposes of personal hygiene and recreation. The problem is especially acute where general hygiene and environmental sanitation are poor and where there is inadequate supply of safe water. The clustered and compacted housing arrangements in Okorombokho community characterized by lack of proper functioning sewage systems and solid waste collection are hazardous and a challenge to public health and to the development of potable water supply infrastructure.

Furthermore, it was revealed that the nature of the toilet system in the community also played a role in the transmission of the major diseases plaguing this community. The toilet types seen in this community were water closet (the least in use by the people), pit toilet, compositing and bush [27]. The use of pit toilet was predominant over the other toilet types and this was followed by defecating in the bush. The high frequency of these two toilet types in this community is not unprecedented but rather is characteristic of a coastal area. This is in consonance with the recent findings of Fowsul-Ameer, et al. [25]. The dominance of pit toilet usage in this study area is in conformity with the findings of Mudundulu, et al. [28] and Inah, et al. [29] in similar researches. The high usage of pit toilets in this community from the FGD held with the dwellers of this community revealed that the low cost in construction and less complexity in maintenance informed their utilization over other toilet types. The types of toilets in this community 


\section{Journal of Quality in Health Care \& Economics}

might have served as major dispersal routes of these diseases. This is confirmed by studies carried out by other scholars in related researches. For instance, Nafi'u, et al. [30] reported that the use of pit latrines or toilets in rural communities is more likely to transport fecal materials into water sources. On the other hand, Dzwairo, et al. [31] identified pit latrines as sources of bacteria to groundwater.

Howard, et al. [27] reported that in Mbale community in Uganda, the location of a latrine uphill within $10 \mathrm{~m}$ shows the greatest positive association with contamination. Distance of contaminating sources such as pit latrines to water points has been an important estimator in indicating the possible source of bacterial contamination of groundwater. Fowsul-Ameer, et al. [25] pointed out that, proximity of latrines to water sources is a major factor affecting ground water quality in many coastal environments as Escherichia coli and faces are likely to be transported to the water source and these are major causes of diarrhea and cholera diseases. From the FGD, it was also revealed that the inhabitants of this community do not clean their toilets daily as most of them opined that they clean their toilet once in a month. This alone may have contributed to the high occurrences of these diseases as there is a tendency for flies to perch on fecal matter and transfer same to food and drinking water sources thus contaminate them thereafter. Against this backdrop, routine and daily cleaning of toilet facilities should be highly emphasized to maintain hygiene standards as well as protect the health of household members from infectious diseases that may arise from use of unsanitary facilities.

During the FGD, information gathered revealed that there were few health centers nearby where the inhabitants infected with the diseases visited for treatment. This might have informed the community members' frequency of visits to the facilities which was assessed as poor since majority of them, $42 \%$ visited yearly while $27 \%$ visited monthly for medical check-ups and treatments. The low frequency of visits of the inhabitants to health centers may underscore their negligence to health as well as poor sensitization on the importance of regular health check-up especially, in a disease-plagued community such as this. This is in consonance with the findings of Ako, et al. [32] and Fowsul-Ameer, et al. [25]. Again, most of the inhabitants $(64 \%)$ resorted to visiting medicine stores when they are sick for their diagnoses and treatment. A low percentage (27\%) visited hospitals for medical care. According to them, their high frequency of visits to medicine stores against health centers is triggered by low cost as visits to health facilities for treatment tend to be capital intensive compared to visits to medicine stores.

The respondents also attributed their alternative visits to medicine stores to inadequate health workers and drug supply at the health centers. They unanimously opined that upon their visits to health centers, long queues of people seeking medical attention are always observed due to lack of health personnel to promptly attend to them. This results in their spending longer hours at health facilities at the expense of their other day-to-day activities. Similar observations were reported by Dzwairo, et al. [31], Malisa, et al. [33] and Deepali, et al. [26]. Consequently, there has been a poor public sensitization and awareness creation in this community on the need to use health facilities as it is the surest way of maintaining sound and quality health among citizens in the community. Thus, it is advisable for the government, health care providers and other related health care professionals to educate the teeming rural populace on the need to utilize modern health care facilities provided in their communities. However, to control, prevent and eradicate communicable and infectious diseases in any given population, proper physical and social planning, understanding the geography, entomology, epidemiology, behavior, and lifecycles of disease-causing organisms as well as cooperation between the policy makers, health care providers and other disease surveillance agencies are important.

\section{Conclusion}

There is a high prevalence of vector-borne and waterborne diseases in the study area due to settlement patterns, poor living conditions, poor sanitation and unhygienic conditions such as presence of stagnant water, use of open water bodies as dumpsites for wastes, open defecation in water bodies, poor siting and closeness of pit latrines to water sources, etc. The prevalence of diseases in this wetland community calls for immediate and rapid attention, responses and actions from the government to salvage this community from the ravage of these diseases. Conclusively, this study provides the baseline information required to tackle disease outbreaks in a perturbed wetland community as well as trigger the effective management and protection of our ecosystems (aquatic and terrestrial) against the outbreak of various infectious and communicable diseases.

\section{References}




\section{Journal of Quality in Health Care \& Economics}

1. Onwuemele A (2012) Pathways for sustainable development under global environmental changes in the Niger Delta, Nigeria. Paper presented at the planet under pressure conference held in London.

2. Allegranzi B, Pittet D (2007) Healthcare-associated infection in developing countries: simple solutions to meet complex challenges. Infect Control Hosp Epidemiol 28(12): 1323-1327.

3. Nwigwe N (2008) Problems and Prospects of Refuse Disposal in Nigerian Urban Centers. International Journal of Natural and Applies Sciences 4(3): 3-10.

4. WHO (2012) International standards for drinking water and environmental quality. WHO weekly report, Geneva, pp: 21-26.

5. WHO (2009a) Global Health Risk; mortality and burden of disease attributable to burden of disease attributable to selected major risk factors. World Health Organization, pp: 22-27.

6. WHO (2009b) Guideline for drinking water quality: Incorporating $1^{\text {st }}$ and $2^{\text {nd }}$ addenda. World Health Organisation, Geneva, pp: 10-17.

7. Long ER, Macdonald DD, Smith SL, Calder FD (1995) Incidence of adverse biological effects within ranges of chemical concentration in marine and estuarine sediments. Journal of Environmental Management 19(1): 81-97.

8. Agwu MO (2013) Community participation and sustainable development in the Niger Delta. British Journal of Education, Society and Behavioral Science 3(1): 33-46.

9. Ukpong IE (1995) An Ordination Study of Mangrove Swamp Communities in West Africa. Vegetatio 116(2): 147-159.

10. Vestergaard LS, Olsen KE, Stensvold R (2007) Outbreak of server gastroenteritis with multiple etiologies caused by contaminated drinking water in Denmark. European Surveillance 12(13): 70-90.

11. Taleb KJ (2014) Characterization of the Potential Water- BorneDiseases in Wadi Gaza-Gaza Strip. IUG Space, pp: 1- 86.
12. Kim Farley RJ (2004) Global strategies for control of communicable diseases. Oxford textbook of public health, pp: 1839-1859.

13. Dako Gyeke M, Kofie HM (2015) Factors Influencing Prevention and Control of Malaria among Pregnant Women Resident in Urban Slums, Southern Ghana. Afr J of Reprod Health 19(1): 44-53.

14. Bayode OJ, Adewunmi EA, Odunwole S (2011) Environmental implications of oil exploration and exploitation in the coastal region of Ondo State, Nigeria: A regional planning appraisal. Journal of Geography and Regional Planning 4(3): 110-121.

15. Nygard K, Schimmer B, Sobstad O, Walde A, Tveit I, et al. (2006) A large community outbreak of waterborne disease and delayed detection in a non-endemic urban area. BMC Public Health 6: 141-145.

16. NDDC (2005) Draft copy of the Niger Delta Regional Development Master Plan. Niger Delta Development Commission Directorate of Planning (NDDC), Port Harcourt.

17. NPC (2007) Nigerian Population highlights. Population Bulletin (No.1:23). National Population Commission Report, National Population Reference Bureau, Lagos, Nigeria.

18. Dayanand KK, Punnath K, Chandrashekar V, Rajeshwara N, Achur SB, et al. (2017) Malaria prevalence in Mangaluru City Area in the Southwestern coastal region of India. Malaria Journal 16(1): 492-512.

19. Kimbi HK, Yannick N, Sumbele IN, Anchang Kimbi JK, Lum E, et al. (2013) Environmental Factors and Preventive Methods against Malaria Parasite Prevalence in Rural Bomaka and Urban Molyko, Southwest Cameroon. J Bacteriol Parasitol 4(1): 162167.

20. Bates I, Fenton C, Gruber J, Lalloo D, Medina LA, et al. (2004) Vulnerability to malaria, tuberculosis, and HIV/AIDS infection and disease. Part 1: determinants operating at individual and household level. Lancet Infect Dis 4(5): 267-277.

21. Brenyah RC, Osakunor DM, Ephraim RK (2013) Factors influencing urban malaria: a comparative study of two communities in the Accra Metropolis. Afr Health Sci 13(4): 992-998. 


\section{Journal of Quality in Health Care \& Economics}

22. Moshi IR, Ngowo H, Dillip A, Msellemu D, Madumla EP, et al. (2017) Community perceptions on outdoor malaria transmission in Kilombero Valley, Southern Tanzania. Malaria Journal 16: 274-281.

23. Pullford J, Hetzel MW, Bryant M, Siba PM, Muller I (2011) Reported reasons for not using a mosquito net when one is available: A review of the published literature. Malaria Journal 10: 83-92.

24. John Dewole 00 (2012) Adverse Effects of Inadequate Water Supply on Human Health: a case study of Kajola Local Government in Oyo State, Nigeria. Greener Journal of Medical Sciences 2(5): 115-119.

25. Fowsul Ameer ML (2017) Water-Borne Diseases and their Challenges in the Coastal of Ampara District in Sri Lanka. World News of Natural Science 9: 7-18.

26. Deepali P, Joshi N (2014) Problems of ground water contamination with focus on water borne diseases, causes and prevention. Applied Science Reports 5(1): $34-41$.

27. Howard G, Nalubega M, Barrett M, Pedley S, Kulabako $R$, et al. (2002) Impact of on-site sanitation on groundwater supplies in Kampala and Iganga, Uganda. In ARGOSS Assessing risk to ground water from on-site sanitation: scientific review and case studies. British Geological Survey Commissioned Report CR/02/079N, British Geological, pp: 1-16.
28. Mudundulu P (2011) Water Borne Diseases: A Cry of a Trapped Community. University of Nebraska, Lincoln, pp: 92-98.

29. Inah A, Uwadiegwu Z, Eko JE, Inah JA (2017) Environmental Sanitation Practices on Malaria Control and Prevention in Abi Local Government Area, Cross River State, Nigeria. Asian Journal of Medicine and Health 6(2): 1-12.

30. Nafi'u A, Anandapandian KTK (2016) The Occurrence of Waterborne Diseases in Drinking Water in Nakaloke Sub-County, Mbale District, Uganda. International Journal of Science and Research 5(10): 1416-1421.

31. Dzwairo B, Hoko Z, Love D, Guzha E (2006) Assessment of the impacts of pit latrines on groundwater quality in rural areas: A case study from Marondera district, Zimbabwe. Physical Chemistry of the Earth 31(15-16): 779-788.

32. Ako AA, Nkeng GE, Eneke Takem GE (2009) Water quality and occurrence of water-borne diseases in the Douala 4th District, Cameroon. Water Sci Technol 59(12): 268-275.

33. Malisa A, Nyaki H (2010) Prevalence and constraints of typhoid fever and its control in an endemic area of Singida region in Tanzania: Lessons for effective control of the disease. J Public Health Epidemiol 2(5): 93-99. 